\title{
Efficacy of Ketogenic Diets on Type 2 Diabetes: a Systematic Review
}

\author{
Delphine Tinguely ${ }^{1} \cdot$ Justine Gross ${ }^{2} \cdot$ Christophe Kosinski $^{2}$ (D
}

Accepted: 8 June 2021 / Published online: 27 August 2021

(C) The Author(s) 2021

\begin{abstract}
Purpose of Review To assess the pleiotropic effects of ketogenic diets (KD) on glucose control, changes in medication, and weight loss in individuals with type 2 diabetes, and to evaluate its practical feasibility

Recent Findings $\mathrm{KD}$ results in improved HbAlc already after 3 weeks, and the effect seems to persist for at least 1 year. This is associated with a reduction in glucose-lowering medications. The weight loss observed after a short time period seems to be maintained with a long-term diet. Adequate support (supportive psychological counseling, enhancing positive affectivity, reinforcing mindful eating) is necessary to achieve a benefit and to assure adherence.

Summary Despite the documented decrease in $\mathrm{HbA1}$, a definitive causal effect of KD remains to be proven. KD should be performed under strict medical supervision. Future research should clarify how compliance can be maximized and how ketosis can be optimally monitored.
\end{abstract}

Keywords Type 2 diabetes $\cdot$ Glucose intolerance $\cdot$ Ketogenic diet $\cdot$ Keto $\cdot$ Very-low-carb diet $\cdot$ Atkins diet

\section{Introduction}

The management of type 2 diabetes mellitus (T2D) includes lifestyle modifications that are combined with pharmacologic interventions as recommended by guidelines of international diabetes societies $[1 \bullet, 2,3]$. Nutrition therapy guidelines often emphasize a reduction in the excessive amounts of carbohydrates, as well as limiting fat intake to be $20-35 \%$ of total calorie intake, with a focus on a decrease in saturated fats

This article is part of the Topical Collection on Lifestyle Management to Reduce Diabetes/Cardiovascular Risk

Christophe Kosinski

christophe.kosinski@chuv.ch

Delphine Tinguely

delphine.tinguely@chuv.ch

Justine Gross

justine.gross@chuv.ch

1 Service of Anesthesiology, Lausanne University Hospital (CHUV), Rue du Bugnon 46, Lausanne, Switzerland

2 Service of Endocrinology, Diabetes and Metabolism, Department of Medicine, Lausanne University Hospital (CHUV) and University of Lausanne, Avenue de la Sallaz 8, 1011 Lausanne, Switzerland
[4*0]. Certain diets propose to reduce the carbohydrate intake even more drastically, in combination with a higher intake of fats, which become the most important source of calories. These regimens are referred to as ketogenic diets $(\mathrm{KD})$ as they result in ketosis secondary to the severe carbohydrate restriction $(<50 \mathrm{~g} /$ day $)$ and the excess of free fatty acids. This combination induces a radical change in energy metabolism with an increase in fatty acid oxidation in the liver and production of ketone bodies [5]. These are acetoacetate (AcAc) and 3- $\beta$ hydroxybutyrate (BHOB), which are used as an energy source, and acetone, which is the product of spontaneous decarboxylation of AcAc [5]. Figure 1 depicts the pathophysiological mechanisms of the KD. In the last decades, KD have become increasingly popular, the most widely known is the Atkins diet [6], and some very-low-carbohydrate $\mathrm{KD}$ are even more restrictive with a carbohydrate intake $<30 \mathrm{~g} /$ day $[7,8]$. In subjects with type 2 diabetes, $\mathrm{KD}$ may be associated with positive effects on some cardiovascular risk factors [9-13]. Of note, the utilization of ketone bodies has shown protective cardiovascular effects in non-diabetic individuals [14], findings that need to be confirmed in individuals with diabetes mellitus. Despite these potentially positive effects, concerns have been raised about long-term adverse effects, particularly lipid metabolism and fatty liver disease, because of the high fat intake; yet recent studies did not corroborate these concerns $[15,16]$. 
In this review, we discuss the pleiotropic effect of $\mathrm{KD}$ on glucose control including glycemic variability in individuals with T2D, its impact on the need for medications and body weight, and the practical feasibility.

\section{Methods}

A systematic literature search was conducted in PubMed, Embase, and the Cochrane Central database covering 2011 to 2021 according to the PRISMA guidelines [17]. Search terms included the keywords "Diabetes Mellitus" OR "diabetes" AND "Diet, Ketogenic" OR "ketogenic diet" OR "keto diet" OR "ketogenous diet" OR "ketotic diet" OR "very low carb diet" OR "very low carbohydrate diet". The search strategies for the databases are summarized in Supplementary Table 1. All publications in English published during the abovementioned period were included in the search. Trials with animals were not included. Studies were excluded if performed with children or adolescents, individuals with type 1 diabetes, and pregnant women, or if the diet was not ketogenic. Guidelines, case reports, reviews, meta-analyses, and abstracts were also excluded. The three authors independently screened the abstracts to check inclusion criteria. The complete text of all publications fulfilling the inclusion criteria was obtained and included in the review. Authors of the publications were not contacted.

Data were collected independently and then compared. In cases of discrepancies, the publication was discussed until agreement was reached. Records identified from citations in the selected studies were included in the review if they were fulfilling all inclusion criteria. The quality of clinical trials was evaluated based on the Cochrane Risk of Bias tool. Details about the systematic review process can be found in Supplementary Appendix.

\section{Results}

After screening of 585 publications, a total of 14 studies were included (Supplementary Figure 1) [18-31]. 12 studies were clinical trials ( 8 randomized, 4 non randomized) and 2 were retrospective or observational studies. Table 1 summarizes the studies that assessed the effect of KD in subjects with T2D.

\section{Effects on Glucose Control}

Ten out 14 included studies showed a positive impact on glycated hemoglobin (HbA1c) (Table 1). In short-term studies, $\mathrm{HbA1c}$ improvements were variable, with reductions of $0.6 \%$ after 3 weeks [23] to $0.9 \%$ after 4 months [28], or even

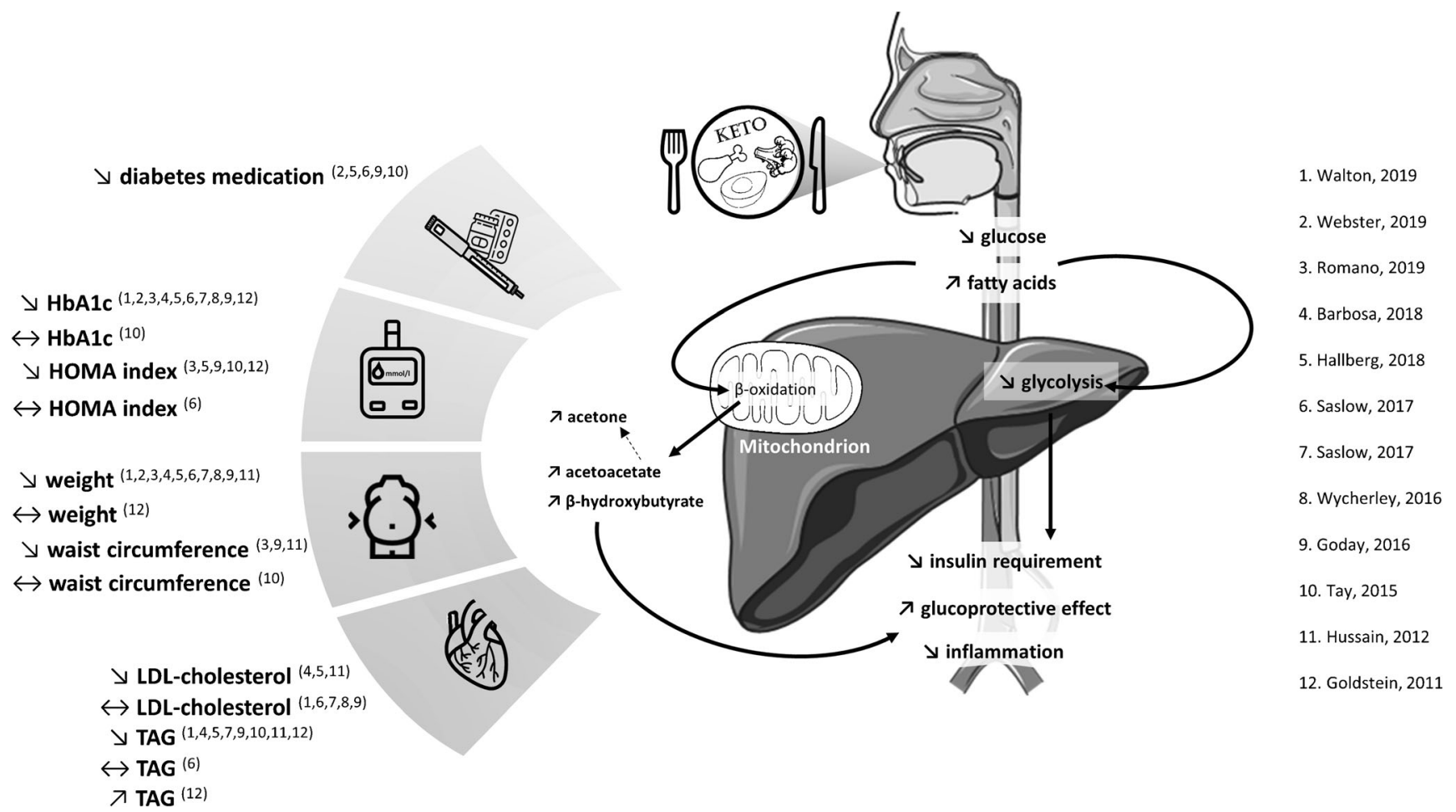

Fig. 1 Potential pathophysiological mechanisms and metabolic effects of ketogenic diet in subjects with type 2 diabetes indicated by clinical trials [19-21 and 22-31]. Changes are indicated as: $\searrow$, significant decrease; $\leftrightarrow$, trend or no significant difference; $\nearrow$, significant increase. Abbreviations:
HbAlc, glycated hemoglobin; FPG, fasting plasma glucose; HOMA, Homeostasis Model Assessment; LDL, low-density lipoprotein; TAG, triacylglycerol 


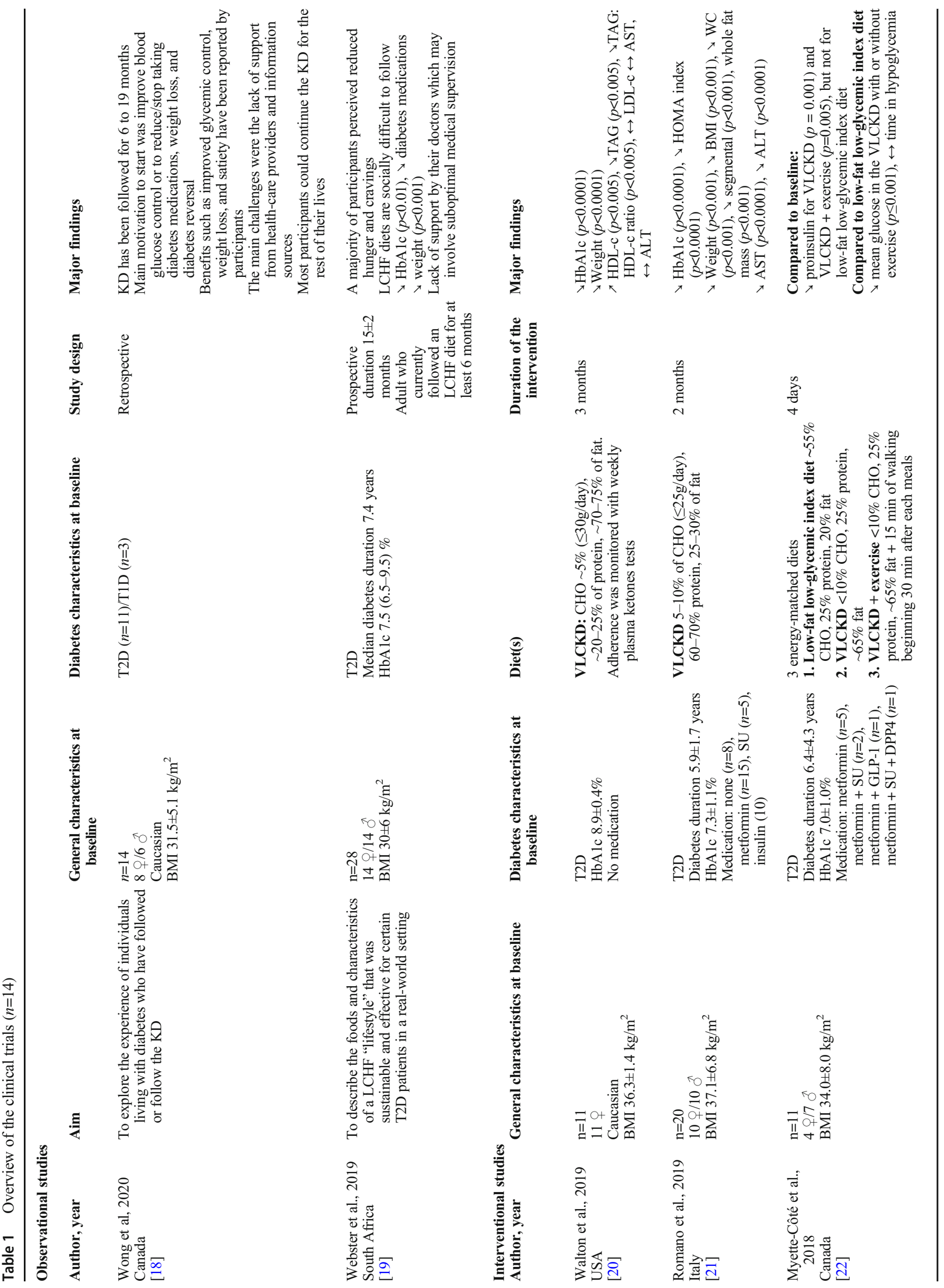




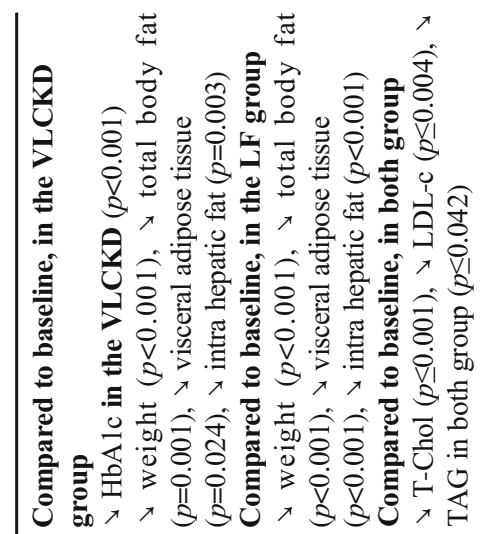

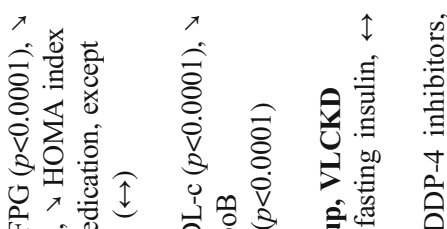

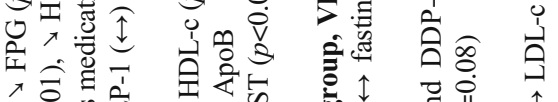

r.

ठํ.

v.

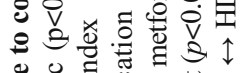

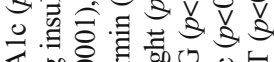

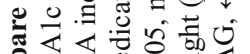

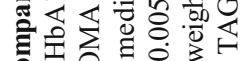

讨

:ै

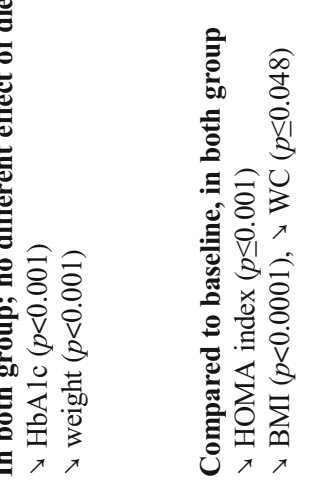

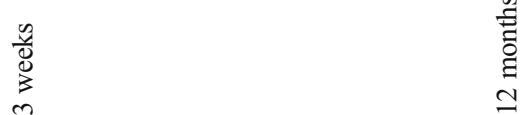

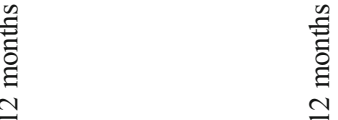

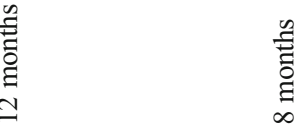

咅

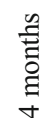

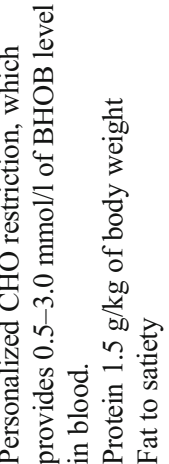

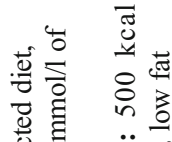

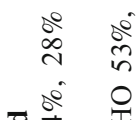

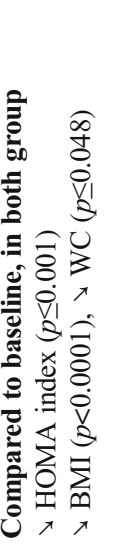

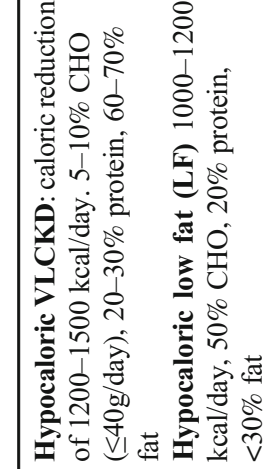

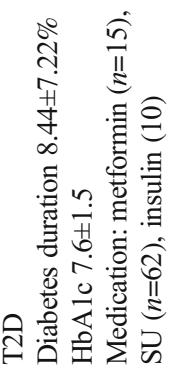

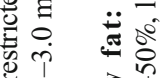

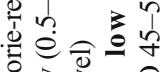

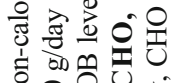

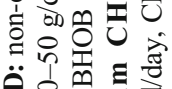

兽焉方

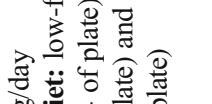

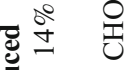

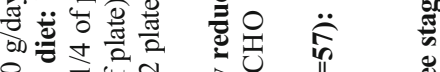

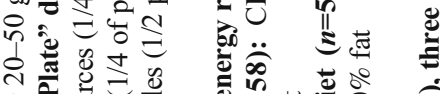

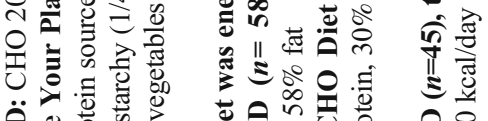

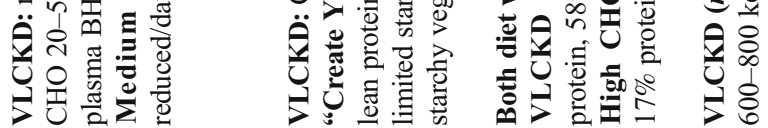

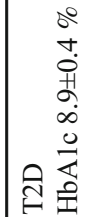

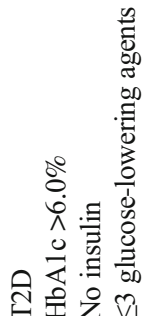

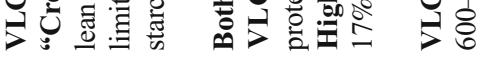

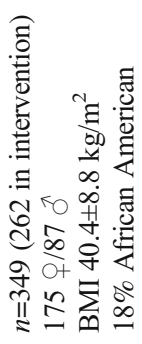

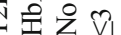

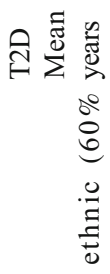

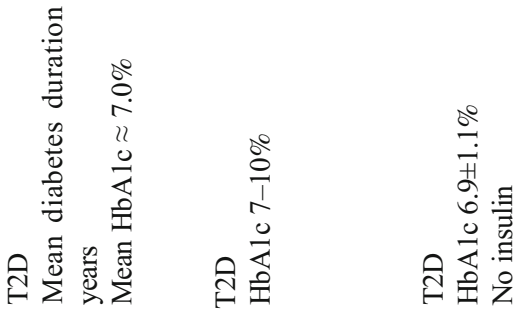

$\stackrel{\infty}{\stackrel{2}{*}}$

䒕

on

总苔导

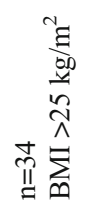

홍

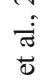

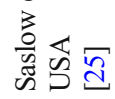

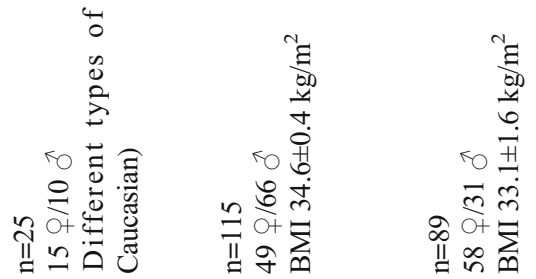

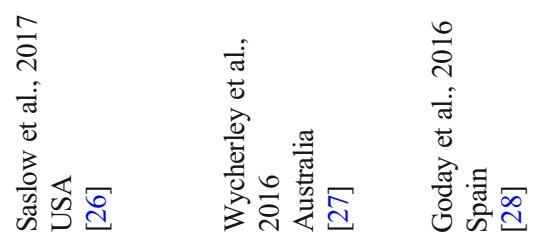




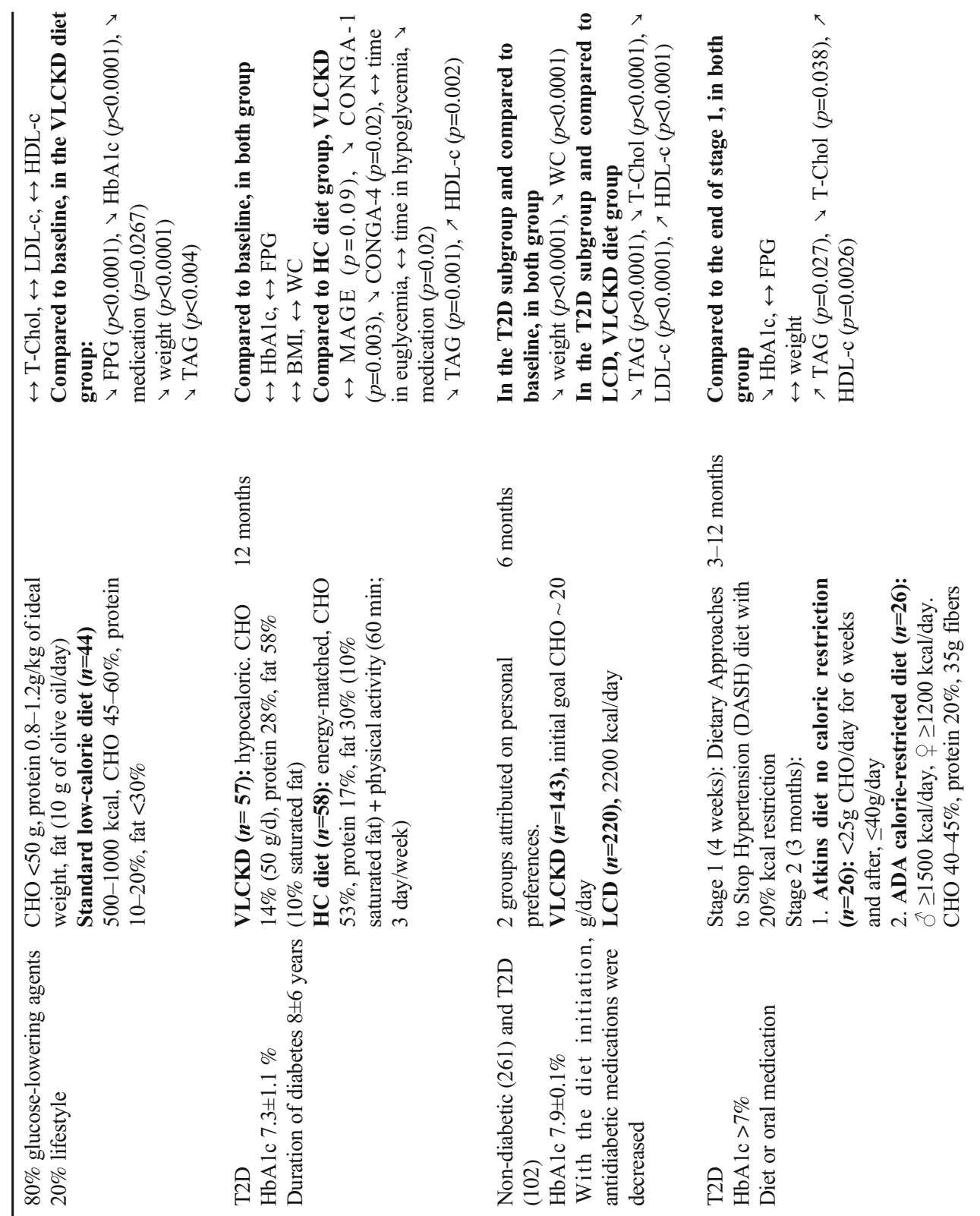

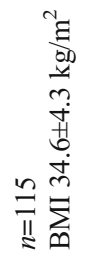

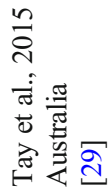

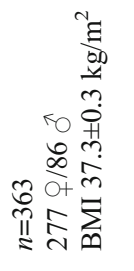

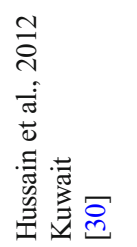

ธ่ธ

㧜 惫 㝵

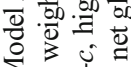
品苛 要命

I $\$$.

家言

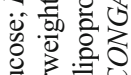

कo 要这

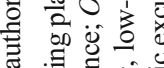

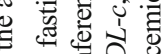

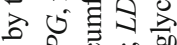

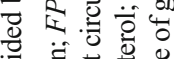

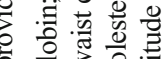
2.

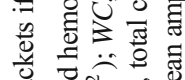
可㻤

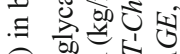
$\pi$ 更

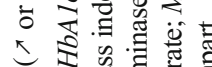

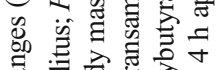

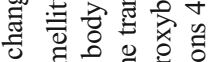

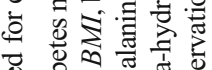

व 话氙

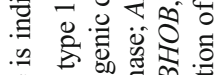

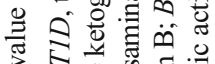
है. 过寻 ₹ के

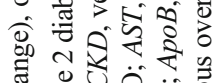
톤

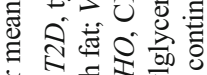
ㅎ. की:

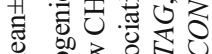

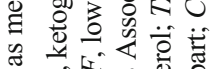

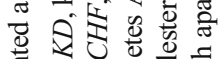

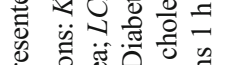

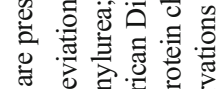

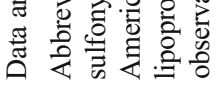


$1.3 \%$ after 32 weeks [26]; in the latter study, $55 \%$ of the patients in the intervention group had an $\mathrm{HbA} 1 \mathrm{c}<6.5 \%$ versus $0 \%$ in the control group $(p=0.02)[26]$. HbAlc reduction from 8.9 to $5.6 \%(p<0.0001)$ was also reported in another study after 90 days [20]. The chance of lowering $\mathrm{HbAlc}<7 \%$ was two-fold higher with KD compared to a standard hypocaloric diet [28]. In a further study, in which glucose-lowering medications were reduced before the diet, a significant reduction of the $\mathrm{HbA} 1 \mathrm{c}$ level from 7.8 to $6.3 \%$ with $\mathrm{KD}$ has been reported after 24 weeks [30]. The HbA1c-lowering effect could be maintained in long-term follow-ups, with a significant reduction from 7.6 to $6.3 \%$ after 1 year, albeit most changes appeared in the first 70 days [24], or from 7.5 to $5.9 \%$ after 15 months [19]. The same authors even reported remission in 10 of 24 participants with T2D (HbA1c $<5.7 \%$ and no medication) after 15 months [19]. Saslow et al. compared a very low-carbohydrate ketogenic diet (VLCKD) with a moderatecarbohydrate, calorie-restricted, low-fat diet (MCRC) administered for 12 months and found that the VLCKD group had a greater reduction in $\mathrm{HbA1c}$ levels than the MCRC group (VLCKD 6.6 to $6.1 \%$; MCRC 6.9 to $6.7 \%$ ) [25]. Some studies reported a significant decrease in $\mathrm{HbAlc}$, but without differences compared to the control group. Tay et al., who compared an isocaloric very-low-carbohydrate high-fat to a highcarbohydrate low-fat diet found a comparable $\mathrm{HbA} 1 \mathrm{c}$ decrease of $1 \%$ in both arms after 52 weeks [29]. A study from Goldstein et al. compared the Atkins KD to a conventional hypocaloric diet and found a similar decrease in $\mathrm{HbAl}$ c levels in both groups at 6 weeks, 3 months, 6 months, and 1 year, with no statistical differences between the groups [31]. Finally, a similar reduction in $\mathrm{HbAlc}$ after 12 months has been reported in a study comparing a very-low carbohydrate diet (LowCHO) versus a traditional isocaloric higher carbohydrate low fat diet (HighCHO) (LowCHO 7.2 to 6.3\%, HighCHO 7.4 to $6.3 \%)(p<0.001)$ [27].

The glycemic variability seems to improve with a KD. Tay et al. demonstrated an improvement in blood glucose stability in the low-carb group, whose subjects spent more time in the euglycemic range $(p=0.07)$ and were less frequently in the hyperglycemic range [29]. However, the proportion of time spent in the hypoglycemic range was similar in both groups [29]. KD are also associated with significant improvements in fasting plasma glucose and mean glucose levels, both in shorttime and long-time studies [21, 22, 25, 28-30].

\section{Effects on the Use of Glucose-Lowering Medication}

A reduction in the use of glucose-lowering medications subsequent to $\mathrm{KD}$ has been observed by several studies. In a study by Saslow et al., $60 \%$ of participants could discontinue sulfonylureas and/or DPP-4 inhibitors, and 30\% metformin after $\mathrm{KD}$, but none of the subjects could do so in the control group [25]. Tay et al. reported a greater reduction in glucose- lowering agents following KD compared to the control group $(p=0.02)$ [29]. At the 1-year follow-up, Hallberg et al. documented a significant reduction for all diabetes medications in participants of the KD group compared with the usual intervention [24]. Specifically, the overall prescriptions (not including metformin) dropped from 57 to $30 \%$; insulin therapy was reduced/interrupted in $94 \%$ of users, sulfonylureas were discontinued in $100 \%$ of users, and metformin decreased slightly (from 71 to $65 \%, p=0.04$ ) in the intervention group [24]. In a study exclusively including patients on metformin, there were no changes in the dose between the study groups [26]. The authors suggested that this may be explained by the safety of metformin, which does not prompt rapid modifications of its dose [26]. Finally, Webster et al. reported a decrease in glucose-lowering medications, including discontinuation of insulin in 8 of 11 participants, after 15 months [19]. In many studies, the patients were asked to interrupt or decrease all medications before $\mathrm{KD}$, which hampers the interpretation of the results $[21,30]$. As even a modest weight loss can have a beneficial effect on glycemic control, a reduced drug use has been observed in both arm (KD and control diet) in several studies [29, 31].

\section{Effects on Weight}

Changes in weight seem to be dependent of the duration of interventional trials. In short-term studies, significant changes in weight loss and body fat were reported after 3 weeks, yet both with $\mathrm{KD}$ and the weight-lowering regiment used in the control group [21, 23]. Romano et al. noticed a predominant reduction of abdominal fat mass with a preserved lean mass with a rigorous low-calorie $\mathrm{KD}$ during an 8-week intervention (15.77\% at the end) [21]. In studies comparing hypocaloric diets, participants achieved a significant weight loss with the VLCKD compared to the control arm after 4 months (BMI 33.3 to $27.9 \mathrm{~kg} / \mathrm{m}^{2}$; standard low-calorie diet BMI 32.9 to 31.0 $\left.\mathrm{kg} / \mathrm{m}^{2}\right)(p<0.001)$ [28], as well as after 6 months of diet (VLCKD BMI-12\% ; LCD BMI-6\%) $(p<0.0001)$ [30]. In long-term studies, some authors did not report any statistical differences between the groups after 12 months of follow-up, when comparing KD versus calorie-restricted diet [31], or LowCHO versus isocaloric HighCHO [27], nor changes in fat mass and waist circumference after 12 months [29]. In a study by Goldstein et al., a greater weight loss at 6 months was reported with $\mathrm{KD}$, compared to a standard calorie-restricted diet, only in the participants with good dietary adherence $(3.7 \mathrm{~kg}, p=0.026)$, as documented by the presence of urinary ketones, but this benefit did not persist at 12 months [31]. A descriptive study by Webster et al. reported a weight loss of $16 \mathrm{~kg}(p<0.001)$ that persisted after 15 months of KD [19]. Finally, Saslow et al. concluded that participants on VLCKD lowered their BMI more than patients in a moderate-carbohydrate, calorie- 
restricted, low-fat diet group (respectively $8.35 \%$ and $3.8 \%$ ) after 12-months of follow-up [25]. Similarly, in a separate study by the same group, in which patients were accompanied with online support, $90 \%$ of the participants on KD lost $5 \%$ of their body weight compared to only $29 \%$ in the control group $(p=0.01)$ [26].

\section{Effects on Lipids, Kidney, and Liver function}

The effects of KD on lipid profile are heterogenous, with improvement of LDL-cholesterol $[23,24,30]$ and triglycerides $[20,23,24,26,28-31]$ reported by some authors, while others reported no significant change in LDL-cholesterol [20, 25-28] and triglycerides [25], or even an increase in triglycerides [31].

No significant changes in renal parameters (urinary albumin-to-creatinine ratio, estimated glomerular filtration rate, creatinine, and blood urea) were reported after 4 months [28] or 12 months of KD [31]. A study noticed an improvement of the glomerular function in the initial 70 days of follow-up [24].

Liver function tests, specifically alanine aminotransferase (ALT) and aspartate aminotransferase (AST), did not differ after 4 months of follow-up [28]. Significant reduction of AST and ALT was reported after 8 weeks [21] and 70 days [24].

\section{Adherence and Feasibility}

Due to their restrictive pattern, KD may be difficult to follow in the long-term, but the adherence seems to be improved by psychological support, enhancing positive affectivity and reinforcing mindful eating. In the study by Saslow et al., the mean retention was $85.3 \%$ after 12 months, but as soon as the support diminished, the dropout rate raised [25]. Some authors reported a dropout rate of only $8 \%$ with personal support versus $46 \%$ if participants were simply accompanied online $(p=0.07)$ [26]. The coaching for developing behavioral adherence strategies, including positive affect regulation and mindful eating strategies, seems to be decisive for the success of the intervention. Factors that may negatively affect adherence may be related to frustration about unreached goal such as improved glycemic control and/or weight loss. Importantly, a more robust psychological support clearly appears to improve dietary adherence [26]. A minimal level of personal attention (online or in person meeting) seems to be necessary to achieve a benefit [20]. Goldstein et al. demonstrated a progressive decrease in the adherence rate to meet the carbohydrate restriction target as documented by absent biological ketosis during 12 months of observation [31]. The monotony of the diet and the need to abstain from fruits and some types of fresh vegetables may explain the lack of adherence, especially during a long period, particularly in the Mediterranean area, where consumption of fruit and vegetables is very common. Furthermore, the weight loss seems to be limited to the first 6 months. Goldstein et al. suggested that the long-term compliance and effectiveness of KD for obese diabetes patients in a Mediterranean environment is low [31]. Other authors highlighted that a support from providers and peers may be necessary to reach good adherence to KD and achieve sustained nutritional ketosis [24]. The fact that some KD interventions permit eating fat to satiety can be considered as a further potential advantage [24]. With appropriate support, most participants achieved and maintained nutritional ketosis up to 1 year, indicating durable efficacy. BHOB can be used as daily biofeedback to monitor and improve adherence [24].

Wong et al. aimed at identifying the main reasons people chose to follow KD: improving blood glucose control or reducing diabetes medication appeared to be the main motivations, followed by weight loss and diabetes reversal [18]. The lack of support from health-care providers and the absence of evidence-based information were the biggest challenges to maintain good adherence [18]. The advent of immediate results and additional health benefits (improvements in cognitive abilities, reduction in chronic pain levels, improvements in energy levels and quality of sleep) help in maintaining the motivation to follow KD [18]. Some participants noted that, compared to other diets tried in the past, adherence to KD was easier, tastier, and overall more enjoyable [18]. The reduced hunger helped participants to be less obsessed with the thought of food [18]. Another challenge is related to restaurant visits or gathering with friends and family, where it is difficult to follow KD. In terms of side effects, many participants found them to be less severe and enduring than expected [18]. Weighing in on their experiences, individuals on $\mathrm{KD}$ felt that the positive effects were outweighing the difficulties associated with adhering to the diet [18]. Webster et al. evaluated the experiences of individuals with $\mathrm{T} 2 \mathrm{D}$ with $\mathrm{KD}$ in a real-world setting [19]. KD remained unchanged during the study. Participants noticed changes in eating behavior, with a reduction of cravings for sweets and snacks. Many participants lost weight without feeling hungry. The absence of a need for measuring quantities or counting calories was perceived as an advantage. Reduction in medications or avoiding the need for insulin therapy seemed extremely empowering and motivating. The main difficulty consisted in the challenges associated with socializing. Many patients experienced an increase in physical activity in connection with an improvement in energy levels.

For this reason, the primary mechanism(s) underlying the positive health impacts remain to be defined, and they may be multifactorial [19].

The study by Goday et al. did not report any serious adverse effect during 52 weeks of follow-up [28]. Mild adverse effects included asthenia, headaches, nausea, and vomiting. These were reported by $80 \%$ of the VLCK diet subjects as 
compared with $41 \%$ of the control population (low-calorie diet). $(p<0.001)$. These adverse effects decreased with time in the VLCK diet group. At the end of the study, constipation and orthostatic hypotension were the most commonly reported adverse events in the VLCK group $(p<0.005)$. Dietary adherence was similar between both study groups [28]. LCKD seems to be safe for a long period in obese participants [30].

\section{Clinical Considerations}

In aggregate, $\mathrm{KD}$ seem to have positive effects in T2D patients and persist in long-term trials, as illustrated in Fig. 1. However, the main drivers leading to improved clinical outcomes need to be better defined. Despite the great decreases in $\mathrm{HbA} 1$ found in several studies, the study designs do not allow to definitely prove that KD has a causal effect. Of note, all groups experienced weight loss, which may explain the impact on $\mathrm{HbA} 1 \mathrm{c}$ levels independent of the type of diet, and all interventional groups were subject to intensive diet counseling, including lifestyle recommendations. Thus, the effect of the dietary intervention is difficult to separate from the impact of other lifestyle changes. It is therefore important that future studies with strong control groups that avoid biases such as exercise, calorie restriction, and intensive supportive coaching further explore the benefits of KD.

Patients with T2D and/or obesity have a pro-inflammatory state [32-34], and KD may have beneficial effects on inflammation and positively modulate cardiovascular risk factors. For example, BHOB, one of the serum ketones detected in abundance on $\mathrm{KD}$, promotes a reduction in inflammation by inhibition of the NLRP3 (NLR family pyrin domain containing 3) inflammasome in lipopolysaccharide (LPS)-stimulated human monocytes, leading to a reduced production of interleukin-1 beta (IL-1beta) and interleukin-18 (IL-18) [35-37]. This observation was confirmed with clinical data reporting a reduction in inflammatory markers with $\mathrm{KD}$ [38].

There are certain limitations in the included studies. The presence of ketosis (by measuring plasma or capillary BHOB) was not evaluated in most studies. However, this point is essential in order to assess the effectiveness of the diet. In long-term studies, positive results were described, but without significant differences compared to controls. This could be explained by the calorie restriction in all dietary interventions. It also seems important to determine whether an optimal target population exists for the $\mathrm{KD}$; factors to consider include the onset of diabetes (recent or long-lasting) and the type of glucose-lowering medications. Moreover, the impact of reintroducing carbohydrates into the diet has not been explored. Due to variability in the nomenclature of the diets, we may have missed some studies in our systematic review. KD are very low-carbohydrates diets, usually $\leq 30 \mathrm{~g} /$ day and, hence, are sometimes referred to as "lowcarb diet". This is a known limitation that remains a challenge until a clear definition for KD has been accepted.
The adherence to KD requires a considerable personal investment. Indeed, the patient must adhere to strict rules to reach a ketogenic state which can be difficult depending on the dietary habits. Moreover, pursuing KD can be unaffordable for some individuals with low income. The long-term adherence can be exhausting, particularly during moments of social contacts. Following KD can, in some instances, reflect an underlying eating disorder, which is more prevalent among patients with T2D, and health care providers have to be aware of this possibility. Last but not least, $\mathrm{KD}$ is not recommended for pregnant or lactating women.

Known risks associated with KD include nephrolithiasis, worsening of dyslipidemia, and hypoglycemic episodes if the glucose-lowering therapy is not adapted. In all cases, diabetic patients on KD should be under strict medical supervision because of its ability in substantially lowering blood glucose levels. Some practical recommendations for adapting diabetes medication have been published [39•]. Insulin, sulfonylureas, and glinides should be progressively reduced by about $50 \%$; biguanides, DPP-4 inhibitors, and GLP-1 agonists should be considered as optional; SGLT2 inhibitors are associated with a risk of ketoacidosis in some T2D patients with relative insulin deficiency and should therefore be avoided during a KD.

Future studies should assess the effect of performing KD intermittently, although this may not permit achieving a ketotic state if the intervention is too short. It is conceivable that inducing intermittent phases of ketosis is beneficial. If this is the case, the duration of the ketotic state and the intervals between these episodes need to be defined. Moreover, an excess in calories and/or carbohydrates between these periods of $\mathrm{KD}$ would need to be avoided. Another key axis of research should address which patients are most likely to benefit from $\mathrm{KD}$, in particular at the cardiovascular level. Furthermore, the effect of KD on glycemic variability needs to be explored. This is of particular interest because it is accepted that glycemic variability is an independent cardiovascular risk factor [40-43]. Based on the nutritional composition of $\mathrm{KD}$, it is plausible that the glycemic variability is less pronounced compared to a carbohydrate-rich diet. If confirmed, this may provide an additional argument for a potential cardiovascular benefit of $\mathrm{KD}$.

\section{Limitations}

The current systematic review included only publications covering the last 10 years. Many of the included studies have a limited methodology, sometimes without a control group, and a high or unclear risk of biases. However, these limitations are inherent to interventional diet studies, which cannot be singleor double-blinded. We also included retrospective observational studies that cannot be evaluated for quality given their design. Finally, we acknowledge that the short period of coverage and/or the sample size may form additional limitations. 


\section{Conclusions}

$\mathrm{KD}$ seems a promising dietary intervention for the improvement of the glycemic control in patients with T2D. However, the benefits believed to be induced by generating a ketogenic state need to be corroborated with well-planned research studies. KD should be accompanied with a structured support by dieticians and dedicated physicians to avoid adverse effects and to adjust glucose-lowering medications. Moreover, intensive support optimizes long-term adherence, which seems to be key to success.

Supplementary Information The online version contains supplementary material available at https://doi.org/10.1007/s11892-021-01399-z.

Acknowledgements The authors would like to thank Prof. Peter A. Kopp who kindly reviewed the manuscript, and provided valuable comments and suggestions.

Funding Open Access funding provided by Université de Lausanne.

\section{Declarations}

Conflict of Interest The authors declare no competing interests.

Human and Animal Rights and Informed Consent This article does not contain any studies with human or animal subjects performed by any of the authors.

Open Access This article is licensed under a Creative Commons Attribution 4.0 International License, which permits use, sharing, adaptation, distribution and reproduction in any medium or format, as long as you give appropriate credit to the original author(s) and the source, provide a link to the Creative Commons licence, and indicate if changes were made. The images or other third party material in this article are included in the article's Creative Commons licence, unless indicated otherwise in a credit line to the material. If material is not included in the article's Creative Commons licence and your intended use is not permitted by statutory regulation or exceeds the permitted use, you will need to obtain permission directly from the copyright holder. To view a copy of this licence, visit http://creativecommons.org/licenses/by/4.0/.

\section{References}

Papers of particular interest, published recently, have been highlighted as:

- Of importance

•. Of major importance

1. American Diabetes A. 5. Facilitating behavior change and wellbeing to improve health outcomes: standards of medical care in diabetes-2021. Diabetes Care. 2021;44(Suppl 1):S53-S72. https:// doi.org/10.2337/dc21-S005. Most recent American guidelines for lifestyle management in prediabetes and diabetes.
2. Colberg SR, Sigal RJ, Yardley JE, Riddell MC, Dunstan DW, Dempsey PC, et al. Physical activity/exercise and diabetes: a position statement of the American Diabetes Association. Diabetes Care. 2016;39(11):2065-79. https://doi.org/10.2337/dc16-1728.

3. Cosentino F, Grant PJ, Aboyans V, Bailey CJ, Ceriello A, Delgado V, et al. 2019 ESC Guidelines on diabetes, pre-diabetes, and cardiovascular diseases developed in collaboration with the EASD. Eur Heart J. 2020;41(2):255-323. https://doi.org/10.1093/ eurheartj/ehz486.

4.• Evert AB, Dennison M, Gardner CD, Garvey WT, Lau KHK, MacLeod J, et al. Nutrition therapy for adults with diabetes or prediabetes: a consensus report. Diabetes Care. 2019;42(5):73154. https://doi.org/10.2337/dci19-0014 Most recent guidelines for nutrition management in prediabetes and diabetes.

5. Laffel L. Ketone bodies: a review of physiology, pathophysiology and application of monitoring to diabetes. Diabetes Metab Res Rev. 1999;15(6):412-26. https://doi.org/10.1002/(sici)15207560(199911/12)15:6<412::aid-dmrr72>3.0.co;2-8.

6. Atkins RC. Dr Atkins' diet revolution: the high calorie way to stay thin forever. New York: Bantam Books; 1973.

7. Bueno NB, de Melo IS, de Oliveira SL, da Rocha Ataide T. Very-lowcarbohydrate ketogenic diet v. low-fat diet for long-term weight loss: a meta-analysis of randomised controlled trials. Br J Nutr. 2013;110(7): 1178-87. https://doi.org/10.1017/S0007114513000548.

8. Paoli A, Rubini A, Volek JS, Grimaldi KA. Beyond weight loss: a review of the therapeutic uses of very-low-carbohydrate (ketogenic) diets. Eur J Clin Nutr. 2013;67(8):789-96. https://doi.org/10.1038/ ejcn.2013.116.

9. Yancy WS, Jr., Foy M, Chalecki AM, Vernon MC, Westman EC. A low-carbohydrate, ketogenic diet to treat type 2 diabetes. Nutr Metab (Lond). 2005;2:34. https://doi.org/10.1186/1743-7075-2-34.

10. Mobbs CV, Mastaitis J, Isoda F, Poplawski M. Treatment of diabetes and diabetic complications with a ketogenic diet. J Child Neurol. 2013;28(8):1009-14. https://doi.org/10.1177/ 0883073813487596.

11. Dashti HM, Mathew TC, Al-Zaid NS. Efficacy of low carbohydrate ketogenic diet in the treatment of type 2 diabetes. Med Princ Pract. 2020;30:223-35. https://doi.org/10.1159/000512142.

12. Westman EC, Yancy WS Jr, Mavropoulos JC, Marquart M, McDuffie JR. The effect of a low-carbohydrate, ketogenic diet versus a low-glycemic index diet on glycemic control in type 2 diabetes mellitus. Nutr Metab (Lond). 2008;5:36. https://doi.org/ 10.1186/1743-7075-5-36

13. Kosinski C, Jornayvaz FR. Effects of ketogenic diets on cardiovascular risk factors: evidence from animal and human studies. Nutrients. 2017;9(5). https://doi.org/10.3390/nu9050517.

14. Yurista SR, Chong CR, Badimon JJ, Kelly DP, de Boer RA, Westenbrink BD. Therapeutic potential of ketone bodies for patients with cardiovascular disease: JACC state-of-the-art review. $J$ Am Coll Cardiol. 2021;77(13):1660-9. https://doi.org/10.1016/j. jacc.2020.12.065.

15. Luukkonen PK, Dufour S, Lyu K, Zhang XM, Hakkarainen A, Lehtimaki TE, et al. Effect of a ketogenic diet on hepatic steatosis and hepatic mitochondrial metabolism in nonalcoholic fatty liver disease. Proc Natl Acad Sci U S A. 2020;117(13):7347-54. https:// doi.org/10.1073/pnas.1922344117.

16. Watanabe M, Tozzi R, Risi R, Tuccinardi D, Mariani S, Basciani S, et al. Beneficial effects of the ketogenic diet on nonalcoholic fatty liver disease: a comprehensive review of the literature. Obes Rev. 2020;21(8):e13024. https://doi.org/10.1111/obr.13024.

17. Moher D, Liberati A, Tetzlaff J, Altman DG, Group P. Preferred reporting items for systematic reviews and meta-analyses: the PRISMA statement. Int J Surg. 2010;8(5):336-41. https://doi.org/ 10.1016/j.ijsu.2010.02.007.

18. Wong K, Raffray M, Roy-Fleming A, Blunden S, Brazeau AS. Ketogenic diet as a normal way of eating in adults with type 1 
and type 2 diabetes: a qualitative study. Can J Diabetes. 2021;45(2): 137-43.e1. https://doi.org/10.1016/j.jcjd.2020.06.016.

19. Webster CC, Murphy TE, Larmuth KM, Noakes TD, Smith JA. Diet, diabetes status, and personal experiences of individuals with type 2 diabetes who self-selected and followed a low carbohydrate high fat diet. Diabetes Metab Syndr Obes. 2019;12:2567-82. https://doi.org/10.2147/dmso.S227090.

20. Walton CM, Perry K, Hart RH, Berry SL, Bikman BT. Improvement in glycemic and lipid profiles in type 2 diabetics with a 90-day ketogenic diet. J Diabetes Res. 2019;2019:8681959-6. https://doi.org/10.1155/2019/8681959.

21. Romano L, Marchetti M, Gualtieri P, Di Renzo L, Belcastro M, De Santis GL, et al. Effects of a personalized VLCKD on body composition and resting energy expenditure in the reversal of diabetes to prevent complications. Nutrients. 2019;11(7). https://doi.org/10. 3390/nu11071526.

22. Myette-Côté É, Durrer C, Neudorf H, Bammert TD, Botezelli JD, Johnson JD, et al. The effect of a short-term low-carbohydrate, high-fat diet with or without postmeal walks on glycemic control and inflammation in type 2 diabetes: a randomized trial. Am J Phys Regul Integr Comp Phys. 2018;315(6):R1210-r9. https://doi.org/ 10.1152/ajpregu.00240.2018.

23. Barbosa-Yañez RL, Dambeck U, Li L, Machann J, Kabisch S, Pfeiffer AFH. Acute endothelial benefits of fat restriction over carbohydrate restriction in type 2 diabetes mellitus: beyond carbs and fats. Nutrients. 2018;10(12). https://doi.org/10.3390/nu10121859.

24. Hallberg SJ, McKenzie AL, Williams PT, Bhanpuri NH, Peters AL, Campbell WW, et al. Effectiveness and safety of a novel care model for the management of type 2 diabetes at 1 year: an open-label, nonrandomized, controlled study. Diabetes Ther. 2018;9(2):583-612. https://doi.org/10.1007/s13300-018-0373-9.

25. Saslow LR, Daubenmier JJ, Moskowitz JT, Kim S, Murphy EJ, Phinney SD, et al. Twelve-month outcomes of a randomized trial of a moderate-carbohydrate versus very low-carbohydrate diet in overweight adults with type 2 diabetes mellitus or prediabetes. Nutr Diabetes. 2017;7(12):304. https://doi.org/10.1038/s41387-0170006-9.

26. Saslow LR, Mason AE, Kim S, Goldman V, Ploutz-Snyder R, Bayandorian $\mathrm{H}$, et al. An online intervention comparing a very low-carbohydrate ketogenic diet and lifestyle recommendations versus a plate method diet in overweight individuals with type 2 diabetes: a randomized controlled trial. J Med Internet Res. 2017;19(2):e36. https://doi.org/10.2196/jmir.5806.

27. Wycherley TP, Thompson CH, Buckley JD, Luscombe-Marsh ND, Noakes M, Wittert GA, et al. Long-term effects of weight loss with a very-low carbohydrate, low saturated fat diet on flow mediated dilatation in patients with type 2 diabetes: a randomised controlled trial. Atherosclerosis. 2016;252:28-31. https://doi.org/10.1016/j. atherosclerosis.2016.07.908.

28. Goday A, Bellido D, Sajoux I, Crujeiras AB, Burguera B, GarcíaLuna PP, et al. Short-term safety, tolerability and efficacy of a very low-calorie-ketogenic diet interventional weight loss program versus hypocaloric diet in patients with type 2 diabetes mellitus. Nutr Diabetes. 2016;6(9):e230. https://doi.org/10.1038/nutd.2016.36.

29. Tay J, Luscombe-Marsh ND, Thompson CH, Noakes M, Buckley JD, Wittert GA, et al. Comparison of low- and high-carbohydrate diets for type 2 diabetes management: a randomized trial. Am J Clin Nutr. 2015;102(4):780-90. https://doi.org/10.3945/ajen.115. 112581.

30. Hussain TA, Mathew TC, Dashti AA, Asfar S, Al-Zaid N, Dashti HM. Effect of low-calorie versus low-carbohydrate ketogenic diet in type 2 diabetes. Nutrition. 2012;28(10):1016-21. https://doi.org/ 10.1016/j.nut.2012.01.016

31. Goldstein T, Kark JD, Berry EM, Adler B, Ziv E, Raz I. The effect of a low carbohydrate energy-unrestricted diet on weight loss in obese type 2 diabetes patients - a randomized controlled trial. $e$ SPEN. 2011;6(4):e178-e86. https://doi.org/10.1016/j.eclnm.2011. 04.003 .

32. Devaraj S, Dasu MR, Jialal I. Diabetes is a proinflammatory state: a translational perspective. Expert Rev Endocrinol Metab. 2010;5(1): 19-28. https://doi.org/10.1586/eem.09.44.

33. Hukshorn CJ, Lindeman JH, Toet KH, Saris WH, Eilers PH, Westerterp-Plantenga MS, et al. Leptin and the proinflammatory state associated with human obesity. J Clin Endocrinol Metab. 2004;89(4):1773-8. https://doi.org/10.1210/jc.2003-030803.

34. Catalan V, Gomez-Ambrosi J, Ramirez B, Rotellar F, Pastor C, Silva C, et al. Proinflammatory cytokines in obesity: impact of type 2 diabetes mellitus and gastric bypass. Obes Surg. 2007;17(11): 1464-74. https://doi.org/10.1007/s11695-008-9424-z.

35. Shimazu T, Hirschey MD, Newman J, He W, Shirakawa K, Le Moan N, et al. Suppression of oxidative stress by betahydroxybutyrate, an endogenous histone deacetylase inhibitor. Science. 2013;339(6116):211-4. https://doi.org/10.1126/science. 1227166.

36. Pinto A, Bonucci A, Maggi E, Corsi M, Businaro R. Anti-oxidant and anti-inflammatory activity of ketogenic diet: new perspectives for neuroprotection in Alzheimer's disease. Antioxidants (Basel). 2018;7(5). https://doi.org/10.3390/antiox7050063.

37. Bae HR, Kim DH, Park MH, Lee B, Kim MJ, Lee EK, et al. betaHydroxybutyrate suppresses inflammasome formation by ameliorating endoplasmic reticulum stress via AMPK activation. Oncotarget. 2016;7(41):66444-54. https://doi.org/10.18632/ oncotarget. 12119 .

38. Forsythe CE, Phinney SD, Fernandez ML, Quann EE, Wood RJ, Bibus DM, et al. Comparison of low fat and low carbohydrate diets on circulating fatty acid composition and markers of inflammation. Lipids. 2008;43(1):65-77. https://doi.org/10.1007/s11745-0073132-7.

39. Murdoch C, Unwin D, Cavan D, Cucuzzella M, Patel M. Adapting diabetes medication for low carbohydrate management of type 2 diabetes: a practical guide. Br J Gen Pract. 2019;69(684):360-1. https://doi.org/10.3399/bjgp19X704525. A recent practical paper about management of glucose lowering medication in T2D on a low-carb diet.

40. Brownlee M, Hirsch IB. Glycemic variability: a hemoglobin A1cindependent risk factor for diabetic complications. JAMA. 2006;295(14):1707-8. https://doi.org/10.1001/jama.295.14.1707.

41. Suh S, Kim JH. Glycemic variability: how do we measure it and why is it important? Diabetes Metab J. 2015;39(4):273-82. https:// doi.org/10.4093/dmj.2015.39.4.273.

42. Monnier L, Colette C. Glycemic variability: should we and can we prevent it? Diabetes Care. 2008;31(Suppl 2):S150-4. https://doi. org/10.2337/dc08-s241.

43. Zaccardi F, Pitocco D, Ghirlanda G. Glycemic risk factors of diabetic vascular complications: the role of glycemic variability. Diabetes Metab Res Rev. 2009;25(3):199-207. https://doi.org/10. 1002/dmrr.938

Publisher's Note Springer Nature remains neutral with regard to jurisdictional claims in published maps and institutional affiliations. 